\title{
The Elements of Computational Thinking in Learning Geometry by Using Augmented Reality Application
}

\author{
https://doi.org/10.3991/ijim.v16i02.27295 \\ Mohd Fadzil Abdul Hanid ${ }^{1(\mathbb{凶})}$, Mohd Nihra Haruzuan Mohamad Said², \\ Noraffandy Yahaya $^{2}$, Zaleha Abdullah ${ }^{2}$ \\ ${ }^{1}$ Johor Bahru District Education Office, Johor Bahru, Johor \\ ${ }^{2}$ School of Education, Faculty of Social Sciences and Humanites, Johor Bahru, Johor \\ fadzil@teknologi.edu.my
}

\begin{abstract}
Augmented Reality (AR) technology has now become a growing trend within the education field. It has the capability to combine both digital and reality world that subsequently leads to the emergence of new possibilities in improving the quality of teaching and learning activities. The objective of this research is mainly to analyse the Computational thinking elements in solving Geometry topic after the intervention of AR application. Qualitative data analysis was employed as the research methodology of this study that involved interview protocol with 10 pupils enrolled in Form 1 Mathematics class at one of the selected schools in Johor Bahru, Malaysia. Content analysis was then administered using the ATLAS.Ti Version 8 software to identify the codes, themes, and meaning conveyed by the pupils' answers in the Computational thinking test. Based on the interview and Computational thinking assessment show the pupils' ability to solve Geometrical problems using Computational thinking elements. The researcher found that Computational thinking elements do exist in problem solving pertaining to the topic of Geometry. However, the order of usage of these Computational thinking elements differs among the pupils. This leads to the conclusion that pupils who utilise the AR application with Computational thinking successfully solve Geometrical problems through the help of the Geometrical thinking process that comprises the elements of Abstraction, Generalisation, Decomposition, Algorithmic, and Debugging.
\end{abstract}

Keywords — augmented reality, computational thinking elements, geometry, qualitative

\section{Introduction}

4.0 Industrial Revolution consists of various new technological findings namely automation, Internet of Things (IoT), Augmented Reality (AR), Virtual Reality (VR), data analysis, artificial intelligence, system integration, the use of robotic and cloud computation [1], [2]. Augmented Reality (AR) is one of the blooming technology which has potential in the educational field. According to [3], in this state-of-the-art era, AR is a popular technology which is widely used in the educational field. The use of smart device gives positive impact in the learning process [4]. The present young 
generation, including kids and teenagers, is known as 'digital natives' since this generation has been exposed to technology from early age [5], [6].

AR technology can help tighten the boundary between reality and virtual world. In this scenario, [3] found some research which show the potential of AR being implemented in the educational topic such as Geometry, planet movement and chemistry molecule structure. Based on the research by [7] stated that AR can help upgrade their visualisation skill. This assumption is identified due to AR characteristics which can upgrade digital information value in the learning content [8]. In fact, the result of studies [9] have shown that Augmented Reality technology can improve the effectiveness of the learning process.

\section{Literature review}

According to [10], Computational Thinking is generally meant as problem solving, to design system by describing basic concept in Computer Science. [11] believed that Computational Thinking term can be identified as thinking process in solving the problem in order to ensure the result can be implemented effectively. [12] describe the computational thinking concept is a problem-solving skill that starts by understanding a complex problem with a holistic approach and analyze the problem, then solve large problems step by step and make it easy to manage and fix. Besides, this research uses Computational Thinking element that has been implemented according to Computational Thinking framework as mentioned by [13], by which it emphasizes on several elements of Abstraction, Generalization, Decomposition, Algorithms and Debugging.

There were several previous research which used Computational Thinking for solving problem in the learning process [14]-[16]. According to research by [16] has shown that the use of Computational Thinking in learning strategy is an essential factor that can influence pupil's learning activity. For an instance, [17] found out that cognitive and metacognitive components via learning strategy has an important influence to successfully solve problems related to academic environment. The use of Computational Thinking is one of the core strategies to solve matters in Mathematics lesson.

[18] emphasized about the importance of using various teaching methods for Mathematics lesson. The obvious challenge for Mathematics lesson is Geometry topic. The research of Trends in International Mathematics and Science Study (TIMSS) 2011 showed that Geometry topic is the weakest one [19]. Research by [20] portrayed that the achievement of Malaysian pupils was low in the year 2007, 2011 and 2015 that contributed Malaysia to be at the low level of international benchmark for Geometry topic. Hence, [19] criticised the use of traditional method for Geometry topic and claimed that the available intervention treatment is not enough for the learning activity.

[21] informed that technology in Mathematics lesson can simplify and upgrade pupil's skill in solving problems. While [22] stated that the characteristics in the technology tools can help assist pupils to apply and use for solving Geometry topic [23] [24]. According to the research conducted by [25], AR is able to give better understanding on spatial and it helps pupils to get better score for their individual writing assessment compared to conventional method. [8] stated that AR characteristics are beneficial from the visualisation perspective as they can be a reference for shape and 
additional information when cognitive has limitation to process and understand ideas in the application of learning. Besides, AR can boast motivational level, confidence and satisfaction for the use of AR mobile device for learning activity [26]

\section{Problem statement}

According to [27] in their research, they have identified that Computational thinking has significant relation for solving problem in Geometrical topic. Their opinion is similar with [28] who have elaborated that pupils have more interest on Mathematics which is relevant to be studied for the learning activity that uses solving problem method in the real context. One of the approaches for solving problem is applying Computational thinking skill as the process to break problems in learning process [29]. The implication of not using learning strategy in solving problem effectively will cause pupils to feel bored and experience difficulties in learning [30].

[31] has mentioned that pupils with low visual ability will experience difficulties to develop mental visualisation. Research has proven that mental relation with Visualisation Spatial ability will be more quick and precise for Augmented Reality user in comparison with non Augmented Reality interface [32]. Moving on, the implementation of Augmented Reality in learning will provide skill to pupils towards cognitive thinking in solving problem [33]. While [34] has explained that some pupils face difficulty to solve problem of Geometry topic since the topic content can be considered as abstract that can influence low academic achievement for Mathematics subject.

\section{$4 \quad$ Research questions}

The study is conducted to investigate;

What are the elements of pupil's Computational thinking for solving Geometrical topic by using Augmented Reality application?

\section{$5 \quad$ Methodology}

Research methodology that uses qualitative design emphasizes on exploratory method as recommended by [35] which is consisted of two research methods for data collection. First method uses semi structured interviews data protocol to 10 selected pupils who are learning Mathematics in Form One class in one of the schools of Johor Bahru, Malaysia by identifying code, theme, sub-theme and meaning according to Thematic analysis [36]. Table 1 shows the examples of semi structured interview conducted. Second method uses content analysis to identify code, theme and meaning from pupil's answer in the Computational thinking assessment by using ATLAS.Ti Version 8 software. Computational thinking assessment conducted is the adaptation of design and principle guidelines to develop Computational thinking assessment by [37] of the programming topic. Researcher has modified the design and principle guidelines to Geometry topic. Analysis is conducted to identify pupil's Computational thinking elements 
to solve problem of Geometry topic. Sample selection has been conducted based on purposive sample after doing Computational thinking assessment and the selection has been done to the pupils who achieve the highest score. There are 31 pupils who participate in Computational thinking assessment, those pupils who have been selected for the interview are chosen ranging from the highest to the lowest score. During interview session, researcher has to stop the session for the tenth pupil since the answer of the interview shows saturated pattern. All 10 pupils who have been interviewed are represented by the alphabets of P3, P4, P7, P9, P11, P14, P15, P17, P24, P28.

Table 1. Semi structured interview questions

\begin{tabular}{|c|c|c|}
\hline No. & $\begin{array}{c}\text { Computational } \\
\text { Thinking Elements }\end{array}$ & Examples of The Questions \\
\hline $\mathrm{i}$ & Abstraction & $\begin{array}{l}\text { Q1 : What did you do after you get question on Geometrical problem } \\
\text { solving? } \\
\text { Q2 : Beginning from understanding the given problem, what are you } \\
\text { going to do as refer to the entity information or available important and } \\
\text { relevant object? } \\
\text { Probes: Does the given information is comprehensive? Does the } \\
\text { information need to be added or aborted or amended? } \\
\text { Q3 : How are you going to determine the given information is only } \\
\text { the important and needed items, while the unimportant is ignored for } \\
\text { solving Geometry problem? Please explain. }\end{array}$ \\
\hline ii & Generalization & $\begin{array}{l}\text { Q4 : Can you identify the formula for some similar problems while } \\
\text { solving Geometry problem? } \\
\text { Q5 : Can you use that Geometry problem solving when you are given } \\
\text { different problems of Geometrical learning? }\end{array}$ \\
\hline iii & Decomposition & $\begin{array}{l}\text { Q6 : How are you going to break complex problem to the smaller parts } \\
\text { which can be easily understood and solved in the Geometrical problem? } \\
\text { Q7: Are you able to solve each of the smaller parts problem? }\end{array}$ \\
\hline iv & Algorithms & $\begin{array}{l}\text { Q8 : How do you draft or plan the step-by-step actions for Geometrical } \\
\text { solving problem method? } \\
\text { Q9 : Do you solve Geometrical problem by using systematic step-by-step } \\
\text { problem solving? }\end{array}$ \\
\hline $\mathrm{v}$ & Debugging & $\begin{array}{l}\text { Q10 : Do you recheck the answers of Geometrical problem solving after } \\
\text { completing and answering those problem? } \\
\text { Q11: What is the method that you use to fix the mistake of Geometrical } \\
\text { problem solving? }\end{array}$ \\
\hline
\end{tabular}

\section{Research procedure}

Research procedure related to the implementation of Computational thinking in AR application has several phases of activities that pupils will experience as refer to teaching and learning session in the classroom. The activities prepared is according to the duration of Mathematics learning period in school. As per Table 2, Geometry topic learning that uses Computational thinking in AR technology consists of 4 subtopics. Moving on, as per Table 3, pupils are able to visualize polygon virtually for 
Geometry topic in the real situation and minimize the difficulty to imagine Geometry. $\mathrm{AR}$ application is also used together with the implementation of learning strategy by using Computational thinking as the process that pupils apply during and after using AR application. This approach is a thinking process method that is able to formulate formula of the problem, thus, problem solving effort can be represented in more effective way especially for any research related to Geometry topic. Pupils will use Computational thinking elements by adopting from [13] namely Abstraction, Generalization, Decomposition, Algorithms and Debugging elements during the process of solving Geometrical topic problem. The implementation of Computational thinking in Geometry topic of Mathematics subject is similar to [38] who has suggested the application of Computational thinking in Mathematics field since it is well-structured approach.

Table 2. Timetable for research on teaching and learning practice

\begin{tabular}{|c|c|}
\hline Week & Content \\
\hline 1 & $\begin{array}{l}\text { SubTopic } 1 \text { : Line \& Vertex } \\
\text { - The use of AR application with Computational thinking } \\
\text { - Virtual content (AR) know, compare and contrast plus explain vertex of the angle for } \\
\text { parallel lines, reflect angle, and complete corresponding angle. }\end{array}$ \\
\hline 2 & $\begin{array}{l}\text { SubTopic } 2 \text { : Basic Polygon } \\
\text { - The use of AR application with Computational thinking } \\
\text { - Virtual content (AR) labling and naming, number of sides, vertex and vertex } \\
\text { of the polygon. } \\
\text { - Virtual content (AR) Geometrical elements for various types of triangular and square. }\end{array}$ \\
\hline 3 & $\begin{array}{l}\text { SubTopic } 3 \text { : Perimeter \& Space } \\
\text { - The use of AR application with Computational thinking } \\
\text { - Virtual content (AR) determine various types of perimeter when long parallel lines is } \\
\text { given or needs to be measured. } \\
\text { - Estimate various types of space by using any suitable methods. }\end{array}$ \\
\hline 4 & $\begin{array}{l}\text { SubTopic } 4 \text { : Problem solving for Combination Geometrical Problem } \\
\text { - The use of AR application with Computational thinking } \\
\text { - Solve problem for any matters related to triangular and square, perimeter and } \\
\text { triangular space, square space, parallel square, kite, trapezium and combination any } \\
\text { types of shape. }\end{array}$ \\
\hline
\end{tabular}

Table 3. The use of AR application, activities and geometrical topic exercises sample

\begin{tabular}{|l|c|l|}
\hline No. & Picture & \multicolumn{1}{c|}{ Description } \\
\hline 1. & & \\
\hline
\end{tabular}

(Continued) 
Table 3. The use of AR application, activities and geometrical topic exercises sample (Continued)

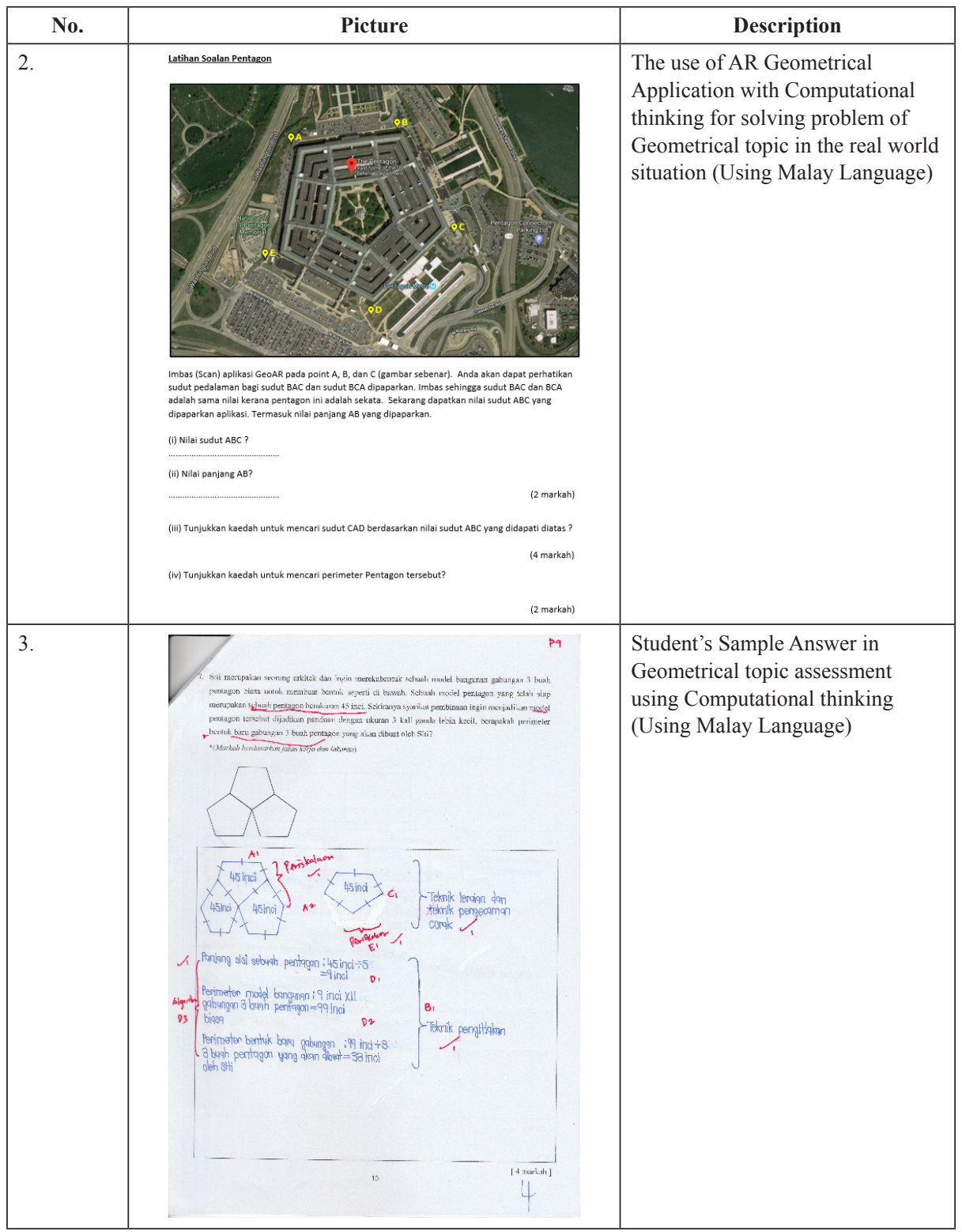

\section{Data analysis}

This research has used qualitative design and data analysis by applying thematic and content analysis [36]. 


\subsection{Data thematic analysis (interview data)}

Table 4. Thematic analysis

\begin{tabular}{|l|l|l|}
\hline Main Theme & \multicolumn{1}{|c|}{ Sub-Theme } & \multicolumn{1}{|c|}{ Pupils } \\
\hline Abstraction & $\begin{array}{l}\text { Identifying important and relevant } \\
\text { object (A1) }\end{array}$ & P3, P4, P7, P9, P11, P14, P15, P17, P24, P28 \\
\cline { 2 - 3 } & Identifying unnecessary object (A2) & P3, P7, P14, P17, P24 \\
\hline Generalization & $\begin{array}{l}\text { Determining similarities for some } \\
\text { problems (B1) }\end{array}$ & P3, P4, P7, P9, P11, P14, P15, P17, P24, P28 \\
\hline Decomposition & $\begin{array}{l}\text { Breaking complex problem to smaller } \\
\text { parts (C1) }\end{array}$ & P3, P4, P7, P9, P11, P14, P15, P17, P24, P28 \\
\hline Algorithms & $\begin{array}{l}\text { Drafting one operating set or step- } \\
\text { by-step action for solving problem } \\
\text { method (D1) }\end{array}$ & P3, P4, P9, P11, P14, P15, P24, P28 \\
\cline { 2 - 3 } & Operating action in correct order (D2) & P3, P4, P7, P9, P11, P14, P15, P17, P24, P28 \\
\cline { 2 - 3 } & $\begin{array}{l}\text { Showing instructional control stream } \\
\text { namely instruction or solving problem } \\
\text { action (D3) }\end{array}$ & P3, P4, P7, P9, P11, P14, P15, P17, P24, P28 \\
\hline Debugging & $\begin{array}{l}\text { Recognize (Identifying), remove, and } \\
\text { fix errors (mistake) (E1) }\end{array}$ & P3, P4, P7, P9, P11, P14, P15, P17, P24, P28 \\
\hline
\end{tabular}

This research has used qualitative design and data analysis by applying thematic and content analysis [36].

Referring to Table 4, pupils report the use of Abstraction element in solving problem of Geometry topic by identifying; searching; drawing; writing; watching; entity or object identifying such as shape; number; sentence, measurement or important value.

"While reading question, I identify essential value and rewrite namely pentagon measurement and sketching pentagon shape." [Pupil, P3]

Pupil also reported the use of Generalization element to solve problem of Geometry topic by showing code or theme outcome namely making; searching; identifying; using; changing; identifying number or formula.

"I identify Mathematics formula of the same measurement by knowing the length for every side. I can use the formula to cater different types of problems, for example similar side concept can be used for other problems too." [Pupil, P4]

Besides, pupils mention the use of Decomposition element in solving Geometry topic problem by showing code and theme gainings namely divide; separate; separation; be separated; item separation such as pentagon and Geometry problem.

"Three pentagons are divided to only one pentagon to help ease counting. I complete one by one, for instance, I get the length of the sides first. Then, finding the perimeter." [Pupil, P7]

Besides measuring the length, pupils mention by using Algorithms element in solving problem of Geometry topic by showing the finding of code and theme such as to design; to plan; to do something; to make; to solve; to perform; to use item systematically, organization; action; systematic; one-by-one; proper step; correctly. 
"I plan my step-by-step actions for the method to solve Geometry problem. Then, I try to solve and draw the figure to ensure my choice of answer is correct. If the arrangement of problem is not organised, it will cause misunderstanding and make me confuse. Therefore, I will solve all problems by using correct and systematic steps." [Pupil, P24]

For the last stage, pupil elaborate by using Debugging element to solve Geometry topic problem. The result has shown code and theme earning namely check; checking; examining; ensuring; recounting; redoing work processing; answering; counting number and sketching.

"I recheck the answers written. I observe the calculated number especially perimeter and formula such as plus, minus, divide and multiply." [Pupil, P11]

\subsection{Data content analysis (computational thinking assessment)}

Table 5. Content analysis

\begin{tabular}{|l|c|c|c|c|c|c|c|c|}
\hline \multicolumn{7}{|c|}{ Computational Thinking Elements } \\
\hline \multirow{2}{*}{ Pupil } & Abstraction & Generalization & Decomposition & \multicolumn{3}{|c|}{ Algorithms } & Debugging \\
\hline & A $^{1}$ & $\mathbf{A}^{2}$ & $\mathbf{B}^{1}$ & C $^{1}$ & $\mathbf{D}^{1}$ & $\mathbf{D}^{2}$ & D $^{3}$ & E $^{1}$ \\
\hline P3 & $\checkmark$ & $\checkmark$ & $\checkmark$ & $\checkmark$ & $\checkmark$ & $\checkmark$ & & \\
\hline P4 & $\checkmark$ & $\checkmark$ & $\checkmark$ & $\checkmark$ & $\checkmark$ & $\checkmark$ & $\checkmark$ & \\
\hline P7 & $\checkmark$ & $\checkmark$ & $\checkmark$ & $\checkmark$ & $\checkmark$ & $\checkmark$ & & \\
\hline P9 & $\checkmark$ & $\checkmark$ & $\checkmark$ & $\checkmark$ & $\checkmark$ & $\checkmark$ & $\checkmark$ & $\checkmark$ \\
\hline P11 & $\checkmark$ & $\checkmark$ & $\checkmark$ & $\checkmark$ & $\checkmark$ & $\checkmark$ & & $\checkmark$ \\
\hline P14 & $\checkmark$ & $\checkmark$ & $\checkmark$ & $\checkmark$ & $\checkmark$ & $\checkmark$ & $\checkmark$ & $\checkmark$ \\
\hline P15 & $\checkmark$ & $\checkmark$ & $\checkmark$ & $\checkmark$ & $\checkmark$ & $\checkmark$ & $\checkmark$ & $\checkmark$ \\
\hline P17 & $\checkmark$ & $\checkmark$ & $\checkmark$ & $\checkmark$ & $\checkmark$ & $\checkmark$ & & $\checkmark$ \\
\hline P24 & $\checkmark$ & $\checkmark$ & $\checkmark$ & $\checkmark$ & $\checkmark$ & $\checkmark$ & & \\
\hline P28 & $\checkmark$ & $\checkmark$ & $\checkmark$ & $\checkmark$ & $\checkmark$ & $\checkmark$ & & \\
\hline
\end{tabular}

Table 5 clearly state that all pupils have shown Abstraction element namely 'Identifying information on essential and relevant entity or object' $\left(\mathrm{A}^{1}\right)$ and 'Identifying information on unimportant entity or object' $\left(\mathrm{A}^{2}\right)$. Besides, all pupils have also portrayed Generalization element namely 'Determining similarity characteristics for some problems in order to ensure the identified solving method formula can be applied to different types of problem' $\left(\mathrm{B}^{1}\right)$. All in all, the analysis also shows that all pupils are exposed Decomposition element $\left(\mathrm{C}^{1}\right)$, 'Separating complex problem to smaller parts in order to be more understood and able to be solved'. On the other hand, Algorithms element which is $\left(\mathrm{D}^{1}\right)$ 'Planning one operational set or step-by-step action for solving problem method' and $\left(\mathrm{D}^{2}\right)$ 'Performing organised action according to correct step' show that all pupils have portrayed that element, but $\left(\mathrm{D}^{3}\right)$ element 'Showing command control flow such as instruction or action for solving any problem' by which only pupils P4, P9, P14 and P15 using that element in doing mathematical calculation. P3, P7, P11, P17, P24 and P28 do not show the calculation for $\left(\mathrm{D}^{3}\right)$ but the final answers are still correct and according to the feedback given during the interview, those pupils are able to straightly 
give answers since the calculation for $\left(\mathrm{D}^{3}\right)$ is just an imagination which is not shown on the answer sheet. The final element is Debugging, only pupils P9, P11, P14, P15 and $\mathrm{P} 17$ show the use of $\left(\mathrm{E}^{1}\right)$ element 'Recognize (Identifying), remove, and fix errors (mistake). P3, P4, P7, P24 and P28 do not show the calculation for ( $\left.\mathrm{E}^{1}\right)$ but the final answers are still correct and based on the pupils' feedback during the interview, they are confident with their final answers and do not show the answer checking process for $\left(\mathrm{E}^{1}\right)$ in the answer sheet.

\section{Discussions}

According to clear data analysis, it shows that pupils have applied Computational thinking elements namely Abstraction, Generalization, Decomposition, Algorithms and Debugging in the process of solving Geometry topic. For solving learning problem, the choice of model or certain solving problem design is a vital aspect to complete any task. With the emergence of technology field like Computer Science, to some extent, it helps promote the most suitable solving problem method for technology related field like Computational thinking [39].

Referring to [40], Abstraction element in Computational thinking can help assist pupils to understand the learning of Mathematics subject. In Mathematics subject, pupils will learn abstract numbering and emphasize arithmetic algorithm as well as building arithmetic system [41], thus, it shows how importance the use of Abstraction element to solve problem as per stated in this research. The finding of this research is also similar to meta-analysis as per suggested by [41] by which there is positive correlation between Computational thinking and academic achievement with one of the elements used which is Abstraction in supporting the learning of Mathematics subject. In addition, the results of a study [42] have proven that the digital education environment in mathematics learning has shown an increase in the level of Abstraction element for Computational thinking.

Pupils' elaboration by stating formula shows that essential information is identified from the previous phase, it enables pupils to produce formula for solving problem of the given Geometrical topic. This opinion is approved and parallel to the research conducted by [43]-[45] by which their research has stated the process of using Generalization to solve problem within pupils' ability to formulate solution for the general form which can be applied for different problems and finally to be used as variables for solving problems.

Pupils' elaboration by resketching simplify pentagon in comparison with original complex pentagon that is given in the question as a method to simplify Geometrical problem solving which gives meaning pupils understand the method to solve Geometrical topic easily. This opinion is supported and relevant with the research by [44] whereby it is clearly stated in the research that the process of using Decomposition element for solving problem is related to pupils' ability to break complex problem which finally becomes something that is easily understood and solved. Based on the research conducted, it is found that pupils who can use Decomposition element are able to solve complex problem easily and able to answer correctly according to work process. 
Pupils elaboration by drafting correct calculation process as an important method to solve Geometrical problem indicates that the step-by-step calculation of organised and systematic work process will assist pupils to solve problem in Geometrical topic. This idea is relevent to the research by [44] by which it explains that the use of Algorithms element for solving problem indicates pupils' ability to plan the step-by-step operation or to act upon problem solving method. Based on the research done, it is found that pupils who can use Algorithms element can finalize their answer correctly according to work process by using organised and systematic steps. For [40], they have stated that the importance of Algorithms element as a tool to develop and to successfully solve the problem by using Computational thinking approach.

As per interview analysis, pupils explain and witnessing the awkwardness during or after answering the questions by rechecking the sketch, work process and answer. Besides, pupils are also explaining about number checking and doing recount upon work process and answers. Debugging is identified as one of the four major elements within exercise dimension that using useful Computational thinking for various design activities [46]. In fact, [47]-[49] have stated that finding and correcting mistakes, representing, and analysing are essential elements for Computational thinking that are shared in various knowledge disciplines.

[50] stated that Geometry is one of the vital topics in expanding pupil thinking process for solving problem. Geometry topic learning gives wide opportunity to pupil to expand the skill of visualisation spatial and reasoning for achieving higher order thinking skill [51]. Summarily, Computational thinking approach in solving problem of Geometry topic with the assistance of AR technology provides more benefits to pupil in the process of solving problem. In fact, the use of AR technology with Computational thinking for solving problem of Geometry topic is relevant to the statement given by [52] that proposed Computational thinking skill should be upgraded in terms of teaching aids for pupil learning process.

In this regard, the discussion of research finding is according to all five Computational thinking elements that consist of solving problem for Geometrical learning topic with the help of developed AR application which is successfully evident as a tool to help solve problem for Geometrical learning topic. There are various research show that the use of software for Geometry topic can help enhance the achievement of Geometry topic as per research conducted by [53], [54] that uses GeoGebra software. In fact, there is one research states that the use of AR application in Geometry topic for primary school has increased the achievement of Geometry learning. This view is highly recommended by [55] that mentioned clearly the use of AR application in learning strategy can be implemented for effective teaching and learning process.

\section{Conclusion}

This research is mainly to identify Computational thinking elements of the pupil on how to solve Geometry topic by using AR application. To sum up, pupils successfully portray Computational thinking element namely Abstraction, Generalization, Decomposition, Algorithms and Debugging to solve Geometry topic. According to this research, it is a wish that Computational thinking approach with the assistance of AR 
technology can highly promote the use of technology in the lesson as well as boasting the advance research on technology and pedagogy approach for solving problem in the learning activity.

\section{Acknowledgement}

We are grateful to Universiti Teknologi Malaysia and Malaysian Ministry of Higher Education for providing the grant (Vote No. 19J16) that enables this study to be carried out.

\section{References}

[1] R. Pierdicca, E. Frontoni, R. Pollini, M. Trani, and L. Verdini, "The use of augmented reality glasses for the application in industry 4.0," Lect. Notes Comput. Sci. (including Subser. Lect. Notes Artif. Intell. Lect. Notes Bioinformatics), vol. 10324 LNCS, pp. 389-401, 2017. https://doi.org/10.1007/978-3-319-60922-5 30

[2] B. Xing and T. Marwala, "Implications of the fourth industrial age on higher education Bo Xing and Tshilidzi Marwala," arXiv Prepr. arXiv1703.09643., 2017. https://doi. org/10.25073/0866-773X/87

[3] M. Akçayır and G. Akçayır, "Advantages and challenges associated with augmented reality for education: A systematic review of the literature," Educ. Res. Rev., vol. 20, pp. 1-11, 2017. https://doi.org/10.1016/j.edurev.2016.11.002

[4] M. Fadzil, A. Hanid, M. Nihra, and H. Mohamad, "Mobile application for G-suite based on multimedia learning cognitive theory," vol. 3, no. 1, pp. 55-60, 2019.

[5] J. Ahn and Y. Jung, "The common sense of dependence on smartphone: A comparison between digital natives and digital immigrants," New Media Soc., vol. 18, no. 7, pp. 1236-1256, 2016. https://doi.org/10.1177/1461444814554902

[6] M. Prensky, "Digital Natives, Digital Immigrants," 2001. https://doi.org/10.1108/ 10748120110424816

[7] S. Nor Farhah, H. Noor Dayana Abd, and Y. Noraffandy, "A review of research on augmented reality in education: Advantages and applications," Int. Educ. Stud., vol. 8, no. 13, pp. 1-8, 2015. https://doi.org/10.5539/ies.v8n13p1

[8] T. Jeřábek, V. Rambousek, and R. Wildová, "Specifics of visual perception of the augmented reality in the context of education," Procedia-Soc. Behav. Sci., vol. 159, pp. 598-604, 2014. https://doi.org/10.1016/j.sbspro.2014.12.432

[9] R. Situmorang, C. Kustandi, S. Maudiarti, R. Widyaningrum, and D. Ariani, "Entrepreneurship education through mobile augmented reality for introducing SMEs in higher education," Int. J. Interact. Mob. Technol., vol. 15, no. 3, pp. 17-29, 2021. https://doi.org/10.3991/ ijim.v15i03.18437

[10] J. M. Wing, "Computational thinking," vol. 49, no. 3, pp. 33-35, 2006. https://doi. org $/ 10.1145 / 1118178.1118215$

[11] V. J. Shute, C. Sun, and J. Asbell-Clarke, "Demystifying computational thinking," Educ. Res. Rev., vol. 22, pp. 142-158, 2017. https://doi.org/10.1016/j.edurev.2017.09.003

[12] N. Rungrangtanapol and J. Khlaisang, "Development of a teaching model in virtual learning environment to enhance computational competencies in the 21 st century," Int. J. Interact. Mob. Technol., vol. 15, no. 13, pp. 93-107, 2021. https://doi.org/10.3991/ijim.v15i13.21791 
[13] C. Angeli et al., "A K-6 computational thinking curriculum framework: implications for teacher knowledge," Journal of Educational Technology and Society, vol. 19, no. 3, pp. 47-57, 2016.

[14] A. Felicia, S. Sha'rif, W. Wong, and M. Mariappan, "Computational thinking and tinkering: exploration study of primary school students' in robotic and graphical programming," Asian J. Assess. Teach. Learn., vol. 7, no. 1993, pp. 44-54, 2017. https://doi.org/10.37134/ajatel. $\underline{\text { vol7.5.2017 }}$

[15] K. Bat, "Computational thinking test (CTT) for middle school students," Mediterr. J. Educ. Res., vol. 12, no. 23, pp. 89-101, 2018. https://doi.org/10.29329/mjer.2018.138.6

[16] D. Gong, H. H. Yang, and J. Cai, "Exploring the key influencing factors on college students' computational thinking skills through flipped-classroom instruction," Int. J. Educ. Technol. High. Educ., vol. 17, no. 1, 2020. https://doi.org/10.1186/s41239-020-00196-0

[17] R. E. Mayer, "Cognitive, metacognitive, and motivational aspects of problem solving," Instructional Science, pp. 49-63, 1998.

[18] D. C. Yang, Y. K. Tseng, and T. L. Wang, "A comparison of geometry problems in middlegrade mathematics textbooks from Taiwan, Singapore, Finland, and the United States," Eurasia J. Math. Sci. Technol. Educ., vol. 13, no. 7, pp. 2841-2857, 2017. https://doi. org/10.12973/eurasia.2017.00721a

[19] C. Bergstrom and D. Zhang, "Geometry interventions for K-12 students with and without disabilities: A research synthesis," Int. J. Educ. Res., vol. 80, pp. 134-154, 2016. https://doi. org/10.1016/j.ijer.2016.04.004

[20] A. Abdul Halim, "Pencapaian Matematik TIMSS 1999, 2003, 2007, 2011 dan 2015: Di Mana Kedudukan Malaysia Dalam Kalangan Negara Asia Tenggara?” Malaysian J. High. Order Think. Ski. Educ., 2017.

[21] I. Papadopoulos and V. Dagdilelis, "Students' use of technological tools for verification purposes in geometry problem solving," J. Math. Behav, vol. 27, no. 4, pp. 311-325, 2008. https://doi.org/10.1016/i.jmathb.2008.11.001

[22] H. S. Lee and K. F. Hollebrands, "Students' use of technological features while solving a mathematics problem," J. Math. Behav., vol. 25, no. 3, pp. 252-266, 2006. https://doi. org/10.1016/j.jmathb.2006.09.005

[23] A. H. Mohd Fadzil, M. S. Mohd Nihra Haruzuan, Y. Noraffandy, and Z. Nur Fadhilah, Application Development of Augment Reality in Geometry Topic Based on Multimedia Learning Cognitive Theory. 2018.

[24] I. Radu, E. Doherty, K. Diquollo, B. Mccarthy, and M. Tiu, "Cyberchase shape quest: Pushing geometry education boundaries with augmented reality," Proc. 14th Int. Conf. Interact. Des. Child., pp. 430-433, 2015. https://doi.org/10.1145/2771839.2771871

[25] J. Ferrer-Torregrosa, J. Torralba, M. A. Jimenez, S. García, and J. M. Barcia, "ARBOOK: Development and assessment of a tool based on augmented reality for anatomy," J. Sci. Educ. Technol., vol. 24, no. 1, pp. 119-124, 2015. https://doi.org/10.1007/s10956-014-9526-4

[26] T. H. C. Chiang, S. J. H. Yang, C. J. H. Huang, and A. Y. S. Su, "Cooperative learning by location-based augmented reality for an inquiry learning course," Proc. - 2014 Int. Conf. Educ. Innov. Through Technol. EITT 2014, pp. 75-78, 2014. https://doi.org/10.1109/EITT.2014.20

[27] W. Sung and J. B. Black, "Factors to consider when designing effective learning: Infusing computational thinking in mathematics to support thinking-doing," J. Res. Technol. Educ., vol. 53, no. 4, pp. 404-426, 2020. https://doi.org/10.1080/15391523.2020.1784066

[28] A. F. DeJarnette and G. González, "Thematic analysis of students' talk while solving a real-world problem in geometry," Linguist. Educ., vol. 35, pp. 37-49, 2016. https://doi. org/10.1016/j.linged.2016.05.002

[29] T. C. Hsu, S. C. Chang, and Y. T. Hung, "How to learn and how to teach computational thinking: Suggestions based on a review of the literature," Comput. Educ., vol. 126, no. July, pp. 296-310, 2018. https://doi.org/10.1016/j.compedu.2018.07.004 
[30] B. Murtiyasa and I. I. Al Karomah, "The impact of learning strategy of problem solving and discovery towards learning outcomes reviewed from students learning motivation," Univers. J. Educ. Res., vol. 8, no. 9, pp. 4105-4112, 2020. https://doi.org/10.13189/ujer.2020.080936

[31] J. Yip, S. H. Wong, K. L. Yick, K. Chan, and K. H. Wong, "Improving quality of teaching and learning in classes by using augmented reality video," Comput. Educ., vol. 128, no. April 2018, pp. 88-101, 2019. https://doi.org/10.1016/j.compedu.2018.09.014

[32] M. R. Marner, A. Irlitti, and B. H. Thomas, "Improving procedural task performance with Augmented Reality annotations," 2013 IEEE Int. Symp. Mix. Augment. Reality, ISMAR 2013, pp. 39-48, 2013. https://doi.org/10.1109/ISMAR.2013.6671762

[33] M. Dunleavy, C. Dede, and R. Mitchell, "Affordances and limitations of immersive participatory augmented reality simulations for teaching and learning," J. Sci. Educ. Technol., vol. 18, no. 1, pp. 7-22, 2009. https://doi.org/10.1007/s10956-008-9119-1

[34] M. R. Ramdhani, B. Usodo, and S. Subanti, "Discovery learning with scientific approach on geometry," J. Phys. Conf. Ser., vol. 895, no. 1, 2017. https://doi.org/10.1088/ 1742-6596/895/1/012033

[35] J. W. Creswell, Research Design: Qualitative, Quantitative and Mixed Methods Approaches. Sage Publications, 2008.

[36] V. Braun and V. Clarke, "Using thematic analysis in psychology," Qual. Res. Psychol., vol. 3, p. 58, 2006. https://doi.org/10.1191/1478088706qp063oa

[37] M. Román González, "Computational thinking test: design guidelines and content validation," no. July, pp. 2436-2444, 2015.

[38] D. Weintrop et al., "Defining computational thinking for mathematics and science classrooms," J. Sci. Educ. Technol., vol. 25, no. 1, pp. 127-147, 2016. https://doi.org/10.1007/ s10956-015-9581-5

[39] J. M. Wing, “Computational thinking," Cacm, vol. 49, no. 3, pp. 33-35, 2006. https://doi. org/10.1145/1118178.1118215

[40] S. Grover and R. Pea, "Computational thinking in K-12: A review of the state of the field," Educ. Res., vol. 42, no. 1, pp. 38-43, 2013. https://doi.org/10.3102/0013189X12463051

[41] H. Lei, M. M. Chiu, F. Li, X. Wang, and Y. jing Geng, "Computational thinking and academic achievement: A meta-analysis among students," Child. Youth Serv. Rev., vol. 118, no. June, p. 105439, 2020. https://doi.org/10.1016/j.childyouth.2020.105439

[42] R. A. H. Bedar and M. Al-Shboul, "The effect of using STEAM approach on developing computational thinking skills among high school students in Jordan," Int. J. Interact. Mob. Technol., vol. 14, no. 14, pp. 80-94, 2020. https://doi.org/10.3991/ijim.v14i14.14719

[43] J. Leonard et al., "Using robotics and game design to enhance children's self-efficacy, STEM attitudes, and computational thinking skills," J. Sci. Educ. Technol., vol. 25, no. 6, pp. 860-876. https://doi.org/10.1007/s10956-016-9628-2

[44] S. Maharani, M. N. Kholid, L. N. Pradana, and T. Nusantara, "Problem solving in the context of computational thinking," Infin. J., vol. 8, no. 2, p. 109, 2019. https://doi.org/10.22460/ infinity.v8i2.p109-116

[45] M. L. Wu and K. Richards, "Facilitating computational thinking through game design," Lect. Notes Comput. Sci. (including Subser. Lect. Notes Artif. Intell. Lect. Notes Bioinformatics), vol. 6872 LNCS, pp. 220-227, 2011. https://doi.org/10.1007/978-3-642-23456-9 39

[46] K. Brennan and M. Resnick, "New frameworks for studying and assessing the development of computational thinking," Proc. 2012 Annu. Meet. Am. Educ. Res. Assoc. Meet. Vancouver, BC, Canada, vol. 1, pp. 1-25, 2012. https://doi.org/10.1.1.296.6602

[47] D. Hemmendinger, "A plea for modesty," ACM Inroads, vol. 1, no. 2, pp. 4-7, 2010. https:// doi.org/10.1145/1805724.1805725

[48] S. Y. Lye and J. H. L. Koh, "Review on teaching and learning of computational thinking through programming: What is next for K-12?" Comput. Human Behav., vol. 41, pp. 51-61, 2014. https://doi.org/10.1016/j.chb.2014.09.012 
[49] D. Weintrop and U. Wilensky, "RoboBuilder: A computational thinking game," Sigcse, p. 736, 2013 [Online]. Available: http://www.ccl.sesp.northwestern.edu/papers/2013/RB Comp Thinking Game.pdf; https://doi.org/10.1145/2445196.2445430

[50] M. Bernard and W. Setiawan, "Development of geometry analysis using geogebra scripting in terms of student cognitive capabilities," J. Phys. Conf. Ser., vol. 1521, no. 3, 2020. https:// doi.org/10.1088/1742-6596/1521/3/032103

[51] M. Hanafi, K. N. Wulandari, and R. Wulansari, "Transformasi geometri rotasi berbantuan software geogebra," Fibonacci J. Pendidik. Mat. dan Mat., vol. 3, no. 2, pp. 93-102, 2017.

[52] J. P. Gibson, "Teaching graph algorithms to children of all ages," pp. 34-39, 2012. https:// doi.org/10.1145/2325296.2325308

[53] L. Baranová and I. Katreničová, "Role of descriptive geometry course in development of students' spatial visualization skills," Ann. Math. Informaticae, vol. 49, pp. 21-32, 2018. https://doi.org/10.33039/ami.2018.04.001

[54] D. Mavani, B. Mavani, and M. Schäfer, "A case study of two selected teachers as they integrated dynamic geometry software as a visualisation tool in teaching geometry," African $J$. Res. Math. Sci. Technol. Educ., vol. 22, no. 3, pp. 297-307, 2018. https://doi.org/10.1080/ $\underline{18117295.2018 .1522716}$

[55] A. H. Mohd Fadzil, M. S. Mohd Nihra Haruzuan, and Y. Noraffandy, "Learning strategies using augmented reality technology in education: Meta-analysis," Univers. J. Educ. Res., vol. 8, no. 5A, pp. 51-56, 2020. https://doi.org/10.13189/ujer.2020.081908

\section{Authors}

Mohd Fadzil Abdul Hanid received the Bachelor Of Technical And Vocational Education from Universiti Tun Hussein Onn Malaysia in 2011 and the Master of Education (Educational Technology) from Universiti Teknologi Malaysia in 2018. His research interests are Augmented Reality (AR), Computational Thinking, ICT in education, and Online Learning. (email: fadzil@teknologi.edu.my).

Mohd Nihra Haruzuan Mohamad Said, Ph.D (The University of Waikato) is a Malaysian Associate Professor at Universiti Teknologi Malaysia. He is currently the Information Technology Manager at the Centre of Academic Leadership Universiti Teknologi Malaysia. His interests lie at the intersection of Educational Technology, e-Learning, Online Learning, Information and Communications Technologies in Education and Academic Leadership. (email: nihra@utm.my).

Noraffandy Yahaya received the Ph.D. degree in computer-based learning from the University of Leeds, U.K. He was the Head of the Department of Educational Science, Mathematics and Creative Multimedia, for nine years. He has been an Associate Professor with the School of Education, Universiti Teknologi Malaysia, since 2013. He has research interests in multimedia in education, online learning, and ICT in education. (email: p-afandy@utm.my).

Zaleha Abdullah received her Ph.D. degree in educational technology from the University of Nottingham, United Kingdom and a Master of Design from the Monash University, Australia. Her research interest includes online and distance learning, instructional design, creativity, visual communication, and leadership. (email: zac@utm.my).

Article submitted 2021-09-17. Resubmitted 2021-10-23. Final acceptance 2021-10-24. Final version published as submitted by the authors. 